Article

\title{
Cyclin-Dependent Kinase and Antioxidant Gene Expression in Cancers with Poor Therapeutic Response
}

\author{
George S. Scaria ${ }^{1,+}$, Betsy T. Kren ${ }^{1,+}$ and Mark A. Klein ${ }^{1,2,3, *}$ \\ 1 Research Service, Minneapolis VA Health Care System, Minneapolis, MN 55417, USA; \\ scari005@umn.edu (G.S.S.); krenx001@umn.edu (B.T.K.) \\ 2 Division of Hematology, Oncology and Transplantation, Department of Medicine, University of Minnesota, \\ Minneapolis, MN 55455, USA \\ 3 Hematology/Oncology Section, Primary Care Service Line, Minneapolis VA Health Care System, \\ Minneapolis, MN 55417, USA \\ * Correspondence: klein062@umn.edu \\ + These authors contributed equally to this manuscript.
}

Received: 1 January 2020; Accepted: 30 January 2020; Published: 5 February 2020

\begin{abstract}
Pancreatic cancer, hepatocellular carcinoma (HCC), and mesothelioma are treatmentrefractory cancers, and patients afflicted with these cancers generally have a very poor prognosis. The genomics of these tumors were analyzed as part of The Cancer Genome Atlas (TCGA) project. However, these analyses are an overview and may miss pathway interactions that could be exploited for therapeutic targeting. In this study, the TCGA Pan-Cancer datasets were queried via cBioPortal for correlations among mRNA expression of key genes in the cell cycle and mitochondrial (mt) antioxidant defense pathways. Here we describe these correlations. The results support further evaluation to develop combination treatment strategies that target these two critical pathways in pancreatic cancer, hepatocellular carcinoma, and mesothelioma.
\end{abstract}

Keywords: hepatocellular carcinoma; pancreatic neoplasms; mesothelioma; genome; cell cycle; reactive oxygen species; mitochondria

\section{Introduction}

Mesothelioma, hepatocellular carcinoma (HCC), and pancreatic cancers are three of the most devastating cancers; these diseases are also recalcitrant to treatment [1-3]. The median survival for patients afflicted with these cancers at advanced stages range primarily from months to approximately one year [1-3]. In settings where local, potentially curative options are not available (a significant proportion of cases of mesothelioma, hepatocellular, and pancreatic cancers), systemic therapy with a targeted agent or chemotherapy are the standard treatment options [4-6]. For mesothelioma, the standard first-line therapy is the chemotherapy regimen cisplatin (involved in DNA adduct formation) plus the antifolate agent pemetrexed (with or without the angiogenesis inhibitor bevacizumab) [3,7]. For hepatocellular carcinoma, first-line options include the tyrosine kinase inhibitors (TKIs) sorafenib or lenvatinib [8]. In pancreatic cancer, the chemotherapy regimen called FOLFIRINOX (5-fluorouracil, oxaliplatin, and irinotecan) is associated with the highest overall survival in patients with advanced disease [9]. Years of clinical trials have not yielded significant advances, and to date, immunotherapy has had modest benefit in mesothelioma and HCC [10,11]. Thus, new approaches against these cancers are needed. Two cellular pathways that are promising as targets in these cancers include (1) the cell cycle pathway and related genes/proteins and (2) mitochondrial (mt) antioxidant defense [12,13]. 


\subsection{Cell Cycle Regulation in Cancer}

Among the various players active in the cell cycle [12,14], cyclin D1 and CDK4/6 (cyclin-dependent kinases 4 and 6) are major proteins responsible for progression through $\mathrm{G} 1$ to $S$ phases, and regulation of this step is corrupted in many cancers $[13,15]$. Cyclin D1 binds to CDK4 or CDK6 and these complexes promote phosphorylation of retinoblastoma protein $(\mathrm{Rb})$. Additional cyclin-CDK complexes (such as CDK2/cyclin E1) further phosphorylate $\mathrm{Rb}$, which allows transcription factors to become active and thereby drive cell cycle progression. The CDK inhibitor p16INK4a (p16, a protein) inhibits the cyclin D1-CDK4 or cyclin D1-CDK6 complexes [14,15]. Inactivation of p16 appears to promote the pathogenesis of many tumor types, including mesothelioma, breast cancer, pancreatic cancer, non-small cell lung cancer, esophageal cancer, and head and neck cancer [14-16]. Several studies confirm that p16 loss is extremely common in mesothelioma [17]. Deletion of the 9p21 locus that encodes p16 was deleted in 35/40 cases (88\%) in one study [17]. Overexpression of the CDK4/6 partner cyclin D1 has been identified in a number of tumor types $[14,15,18]$, such as mantle cell lymphoma (with a well-known translocation involving cyclin D1 in nearly $100 \%$ of these cases), non-small cell lung cancer, and breast cancer.

\subsection{Mitochondrial Antioxidant Defense}

Thioredoxin 2 (Trx2) plays an essential role in mitochondrial $(\mathrm{mt})$ and cell viability, and an essential role for $\operatorname{Tr} x 2$ in the response to oxidative stress is well supported in the literature $[19,20]$. Trx2 haploinsufficient (Trx2 +/-) mice show impaired $\mathrm{mt}$ function, increased mt oxidative stress, decreased ATP production, and increased oxidative damage to nuclear DNA, lipids, and proteins [21]. TNF- $\alpha$-induced reactive oxygen species (ROS) generation, NF-KB activation [22], mitochondrial permeability transition (mPT) [23], and apoptosis [24] can all be regulated by Trx2. Finally, overexpression of Trx2 enhances $\mathrm{mt}$ membrane potential $(\Delta \psi \mathrm{m})$ [25]. Auranofin, a systemic therapeutic molecule that was developed for rheumatoid arthritis, represses disease progression via decreased inflammation and increased cell-mediated immunity. Its main mechanism of action is the inhibition of the reduction of $\operatorname{Tr} 22$ by thioredoxin reductase 2 [26-28], thereby defeating the ability of maintaining low intracellular reactive oxygen species (a key adaptation for cancer cell survival). HCC develops in the context of chronic inflammatory liver disease and progression is characterized by an increasing immunosuppressive tumor environment, thereby implicating mitochondrial antioxidant defense as a viable target [29]. Furthermore, the abnormal vascularization of solid tumors results in the development of metabolically compromised microenvironments that severely limits the ability of the cancer cells to survive a decrease in mitochondrial function, suggesting that targeting mitochondrial antioxidant defense is a key component for eradicating the quiescent tumor cell population [30,31].

\subsection{Interrelationship of Cell Cycle-Related Genes and Mitochondrial Antioxidant Defense Genes}

Novel approaches to combination therapies are needed due to the modest benefits of current treatments for mesothelioma, $\mathrm{HCC}$, and pancreatic cancer as described previously. It can be challenging to design combination therapies for clinical studies based on the exorbitant number of potentially targetable pathways that may interact. We chose to focus on (1) pathways (or, more precisely, pathway-related genes that correspond to a potential drug target) that have an FDA-approved drug (such as palbociclib or auranofin), (2) at least one target of a two-target pair having a known association with the cancer (such as CDK4 in pancreatic cancer, mesothelioma, and HCC), (3) the fact that there is a plausible interaction between genes or gene products, and (4) novel combinations. Based on this, we chose to focus on cell cycle-related genes and mitochondrial antioxidant defense genes. Palbociclib and auranofin are both FDA-approved. CDK4 has been evaluated extensively in mesothelioma, HCC, and pancreatic cancer [32]. Palbociclib (PD-0332991), a selective CDK4/6 inhibitor, restricts tumor growth in preclinical models of HCC and pancreatic cancer [32,33]. Furthermore, the combined inhibition of CDK4/6 and PI3K/AKT/mTOR pathways inhibits mesothelioma cell growth [34]. The gene FOXM1 is 
known to be highly interactive with CDK2, CDK4, and thioredoxins [35,36]. For example, FOXM1 induces transcription of cyclin D1 and CDK4 to enhance activity of these proteins [37]. In addition, auranofin is a thiol compound that inhibits the thioredoxin pathway, at least partially via FOXM1 downregulation [38].

\subsection{The Cancer Genome Atlas (TCGA)}

The Cancer Genome Atlas has been a significant and widely utilized resource [39]. Many cancers, including mesothelioma, hepatocellular carcinoma, and pancreatic cancer, have been included in the TCGA efforts [40-42]. A web-based tool, cBioPortal, has been created and is continually updated to aid in the analysis of TCGA data $[43,44]$. Currently, experimental treatments do not take full advantage of the knowledge about the transcriptomics of these diseases. We interrogated the TCGA data using cBioPortal and employing a set of genes (Table 1) encompassing these two pathways to determine their potential utility in meeting the urgent need for new precision oncology-based treatment approaches for these diseases.

Table 1. Gene set employed for The Cancer Genome Atlas (TCGA) analysis.

\begin{tabular}{cccccccc}
\hline CDKN2A & CDKN2B & CDK1 & CDK2 & CDK4 & CDK5 & CDK6 & CDK7 \\
\hline CDK11B & CCNA1 & CCNA2 & CCNB1 & CCNB2 & CCND1 & CCND2 & CCND3 \\
\hline CCNE1 & CCNE2 & CDK5R1 & CDK5R2 & CCNH & CCNL1 & CCNL2 & FOXM1 \\
\hline TXN & TXNRD1 & TXN2 & TXNRD2 & PRDX3 & GLRX2 & GPX2 & SOD2 \\
\hline MSRA & HIF1A & NFKB1 & CSNK2A1 & CSNK2A2 & CSNK2B & NFE2L2 & MAP3K5 \\
\hline \multicolumn{7}{c}{ Genes indicated in bold type were used for the mRNA expression key pathway analysis. } &
\end{tabular}

\section{Results}

\section{1. $m R N A$ Expression}

Heatmaps of the genes were generated for all three cancers (Figure 1) with the z-score set to a threshold of 2.0 employing unsupervised hierarchical clustering and using the cBioPortal tool. Most notable was the clear distinction of cell cycle-related mRNA clustering in all three cancers.

Second, key non-cell cycle CDKs (CDK5 and CDK11B) clustered with key antioxidant genes, including thioredoxin 2 (TXN2), methionine sulfoxide reductase (MSRA), and thioredoxin reductase 2 (TXNRD2). mRNA expression was also compared utilizing Spearman and Pearson coefficients (two distinct, and complementary, correlation formulas available in cBioPortal) among key pathway genes for all three cancers to determine the strength of association (Table S1, Supplementary Materials). For mesothelioma, key interactions (either positive or negative, with Spearman and/or Pearson coefficients with absolute values > 0.3) included CDK2-TXN2 (neg), CDK2-FOXM1 (pos), CDK2-CSNK2A1 (gene for CK2) (pos), CDK4-NFKB1 (neg), CDK4-FOXM1 (pos), CDK5-TXN2 (pos), CDK5-GLRX2 (pos), CDK5-NFKB1 (neg), CDK5-CSNK2B (pos), TXN-GLRX2 (pos), TXN-CSNK2B (pos), TXN2-GLRX2 (pos), TXN2-CSNK2B (pos), and HIF1-TXN2 (neg). (GLRX2 encodes glutaredoxin 2, CSNK2A1 encodes the protein CK2A, CSNK2B encodes the protein CK2B, and HIF1 encodes hypoxia inducible factor 1.) For pancreatic cancer, notable associations included CDK2-TXN2 (neg), CDK2-FOXM1 (pos), CDK2-HIF1 (pos), CDK4-CSNK2B (pos), CDK5-TXN2 (pos), CDK5-TXNRD2 (pos), CDK5-GLRX2 (pos), CDK5-NFKB1 (neg), CDK5-CSNK2B (pos), TXN-GLRX2 (pos), TXN-CSNK2B (pos), TXN-GPX2 (pos), TXN-FOXM1 (pos), TXN2-TXNRD2 (pos), TXN2-CSNK2B (pos), HIF-TXN (neg), HIF-TXNRD1 (pos), HIF-TXN2 (neg), HIF-TXNRD2 (neg), HIF-SOD2 (pos), and HIF-NFKB1 (pos). (GPX2 encodes glutaperoxidase 2, TXN encodes thioredoxin 1, and SOD encodes superoxide dismutase.) For hepatocellular carcinoma, associations included CDK2-TXN2 (neg), CDK2-TXNRD2 (neg), CDK2-FOXM1 (pos), CDK2-CSNK2A1 (gene for CK2) (pos), CDK2-HIF1 (pos), CDK4-PRDX3 (neg), CDK4-CSNK2A1 (pos), CDK4-CSNK2B (pos), CDK5-GLRX2 (pos), CDK5-NFKB1 (neg), 
CDK5-CSNK2B (pos), CDK5-HIF1 (neg), TXN-TXNRD1 (pos), TXN-GLRX2 (pos), TXN-GPX2 (pos), TXN-SOD2 (pos), TXN2-NFKB1 (neg), TXN-CSNK2B (pos), TXN2-TXNRD2 (pos), TXN2-NFKB1 (neg), TXN2-CSNK2A1 (neg), TXN2-CSNK2B (pos), HIF1-TXN (neg), HIF1-TXN2 (neg), HIF1-TXNRD2 (neg), HIF1-NFKB1 (pos), HIF1-CSNK2A1 (pos), and HIF1-CSNK2B (neg). Please see the Supplemental Data Table for a tabular format of the above information.

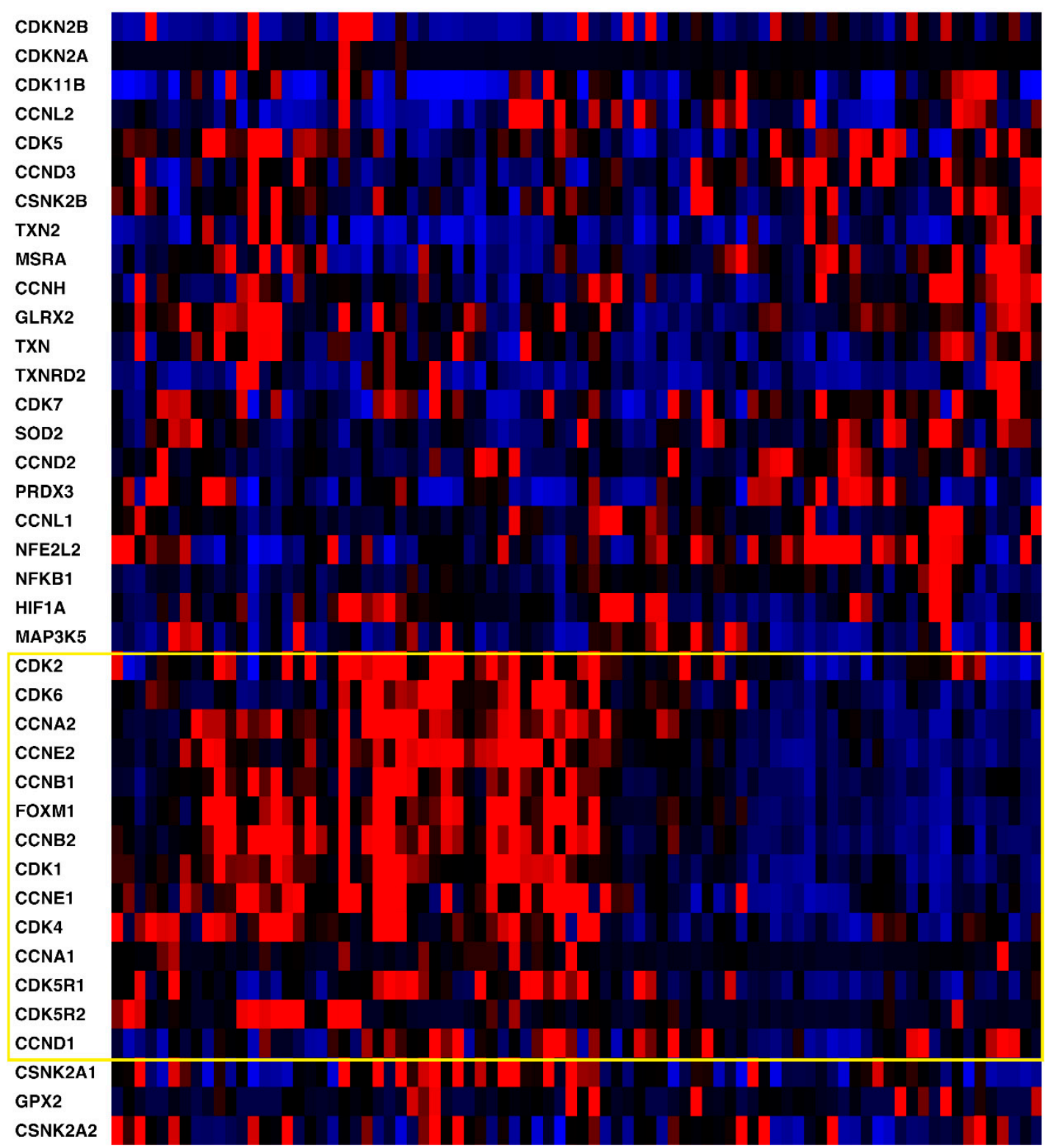

(A) Mesothelioma clustered heatmap.

Figure 1. Cont. 


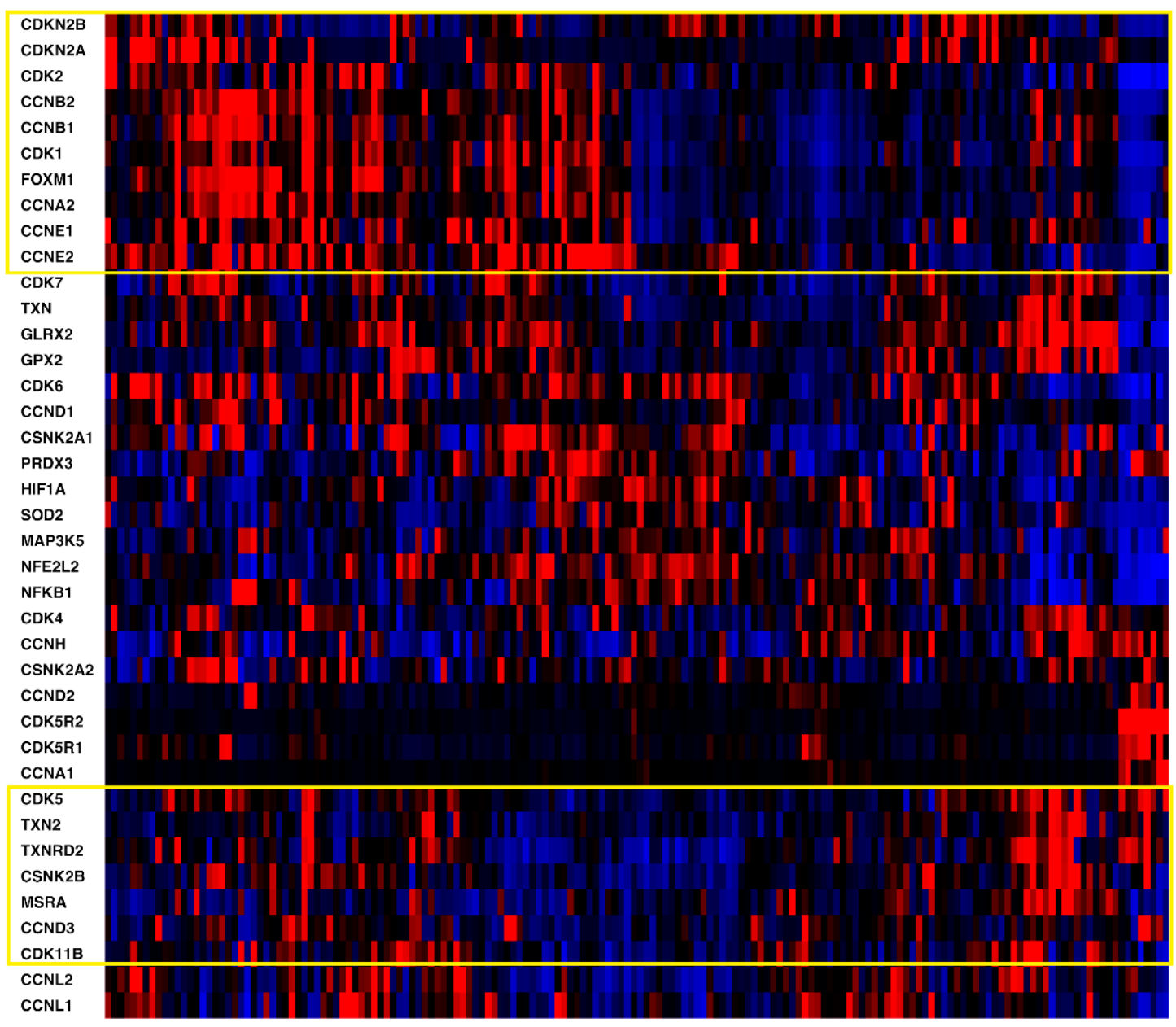

(B) Pancreatic cancer clustered heatmap.

Figure 1. Cont. 


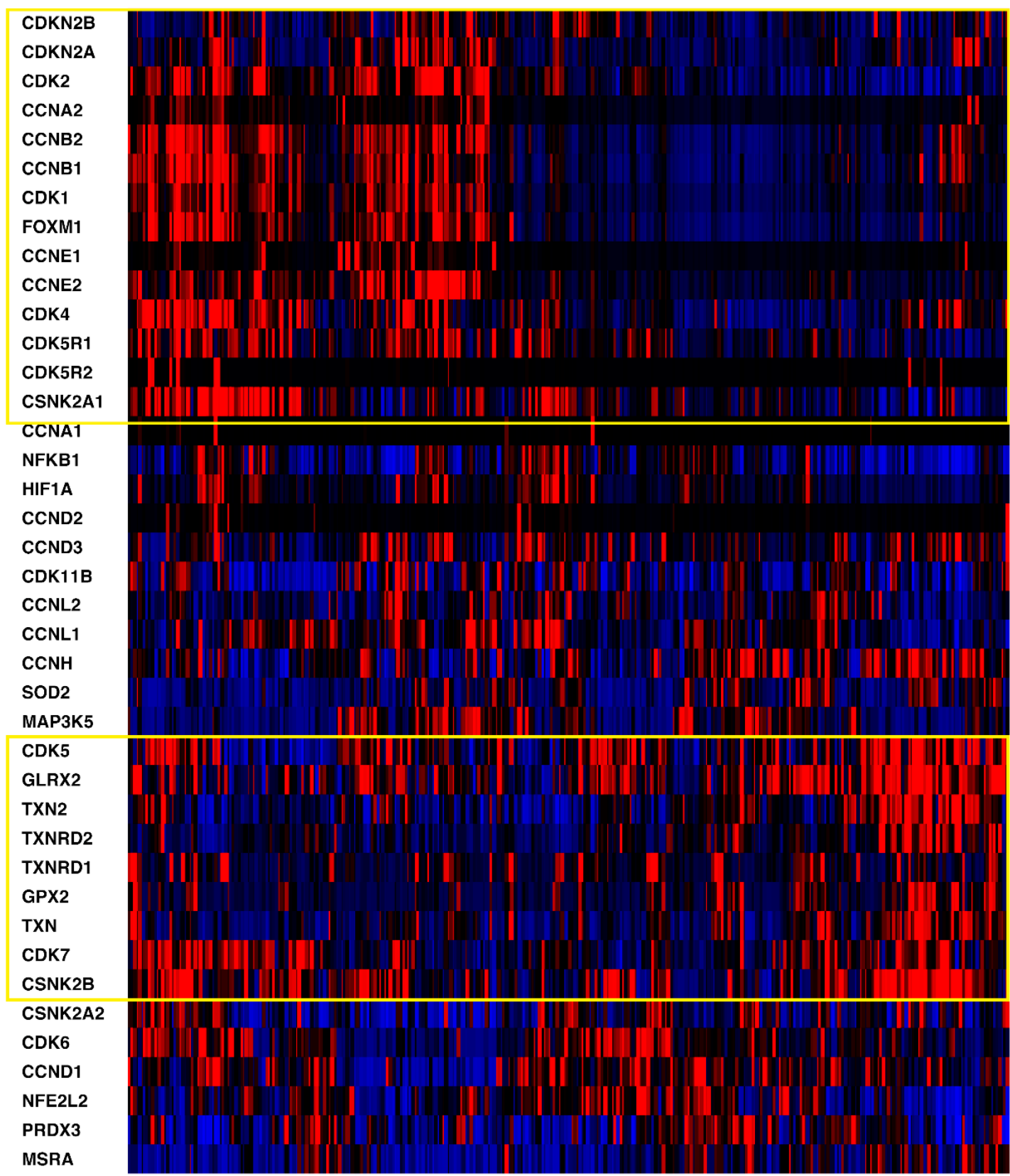

(C) Hepatocellular carcinoma clustered heatmap.

Figure 1. (A) Mesothelioma heatmap with cell cycle-related genes boxed; (B) Pancreatic cancer heatmap (cell cycle-related genes in the top box, antioxidant defense-related genes in the bottom box; (C) Hepatocellular carcinoma heatmap (cell cycle-related genes in the top box, antioxidant defense-related genes in the bottom box). Red, higher expression; blue, lower expression. Box is in yellow.

\subsection{Overall Survival}

The Kaplan-Meier curves for overall survival of patients with each cancer with mRNA panel expression for z-scores $\geq 2$ vs. tumors with z-scores $<2$ are shown in Figure 2A. Z-scores were applied to Kaplan-Meier curves based on the gene set from Table 1. Overall survival was significantly higher for patients with tumors exhibiting z-scores $<2$ in hepatocellular carcinoma and mesothelioma, but overall survival was not higher for patients with pancreatic cancer. The survival curves encompass patients with all stages of the particular cancer evaluated. 


\subsection{Progression-free Survival}

The Kaplan-Meier curves for progression-free survival of patients with cancers expressing the target mRNA with z-scores $\geq 2$ vs. tumors with z-scores $<2$ are shown in Figure $2 \mathrm{~B}$. In contrast to the overall survival curves, alteration of mRNA expression of the selected gene set was not associated with progression-free survival for any of the cancers.
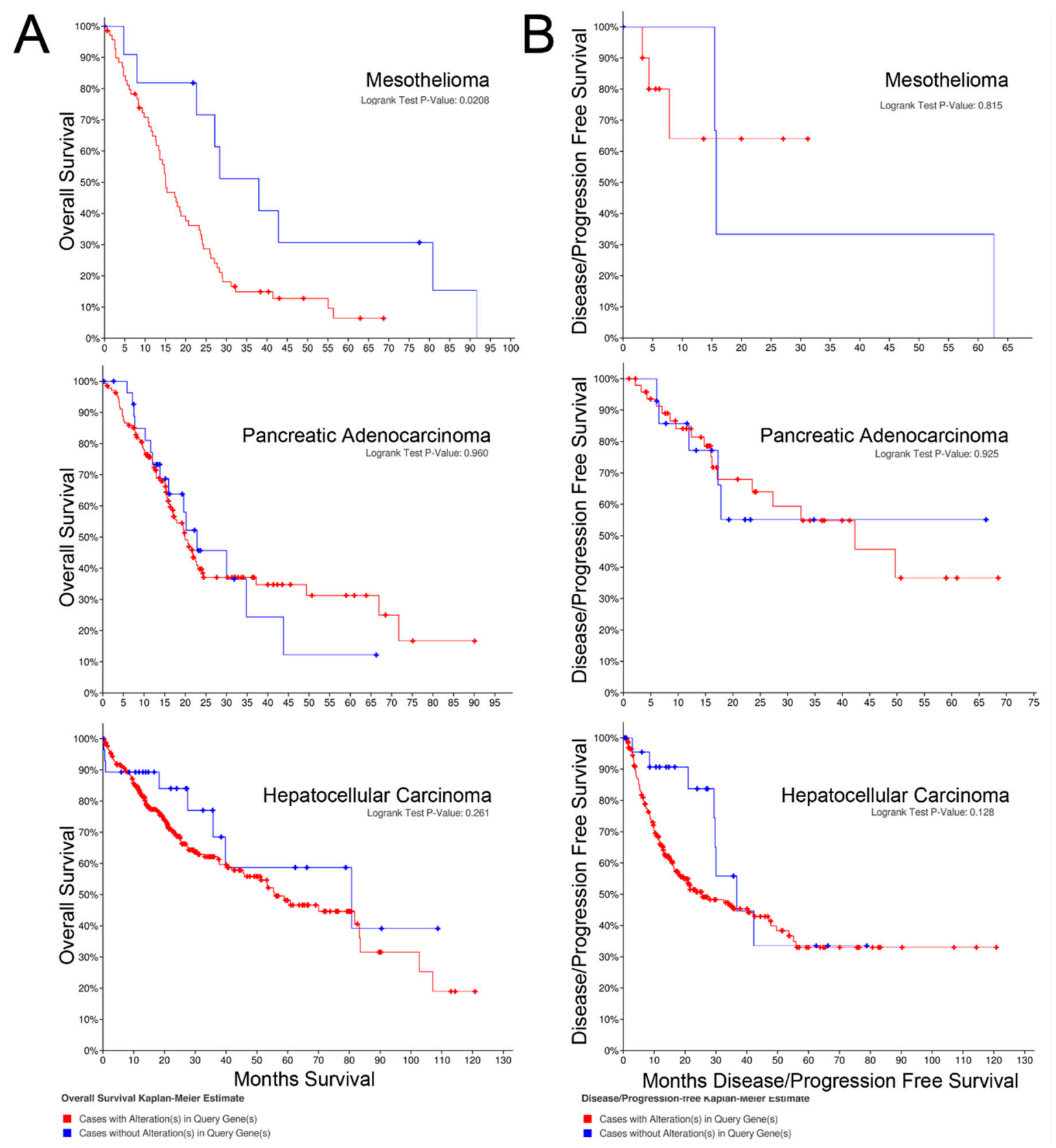

Figure 2. (A) Overall survival; (B) Progression-free survival.

\subsection{Copy Number Alterations}

The top-ranked copy number variations (CNVs) were evaluated for all three cancers (Figure 3A). Unexpectedly, the top 3 copy number variants for both mesothelioma and pancreatic cancer were the same: CDKN2A (encoding p16INK4a), CDKN2B (encoding p15INK4b), MTAP (encoding methylthioadenosine phosphorylase), DMRTA1 (doublesex and mab-3 related transcription factor 1), and LINC01239 (long intergenic non-protein coding RNA 1239). In addition, three interferons (IFNA1, 
IFNA2, and IFNE) and MIR31HG (microRNA-31 Host Gene) were also in the top 10 for these two cancers. The interferon alpha gene alterations observed are likely because they cluster near band 9q21 that is proximal to the locus of CDKN2A, which was included in the screened gene set and is commonly deleted in both cancer sets. However, it is unclear whether the alteration of the IFN-alpha locus has any effect on tumor behavior. No overlap in top ranked CNVs between mesothelioma, pancreatic, and hepatocellular cancers were noted (Figure 3A).
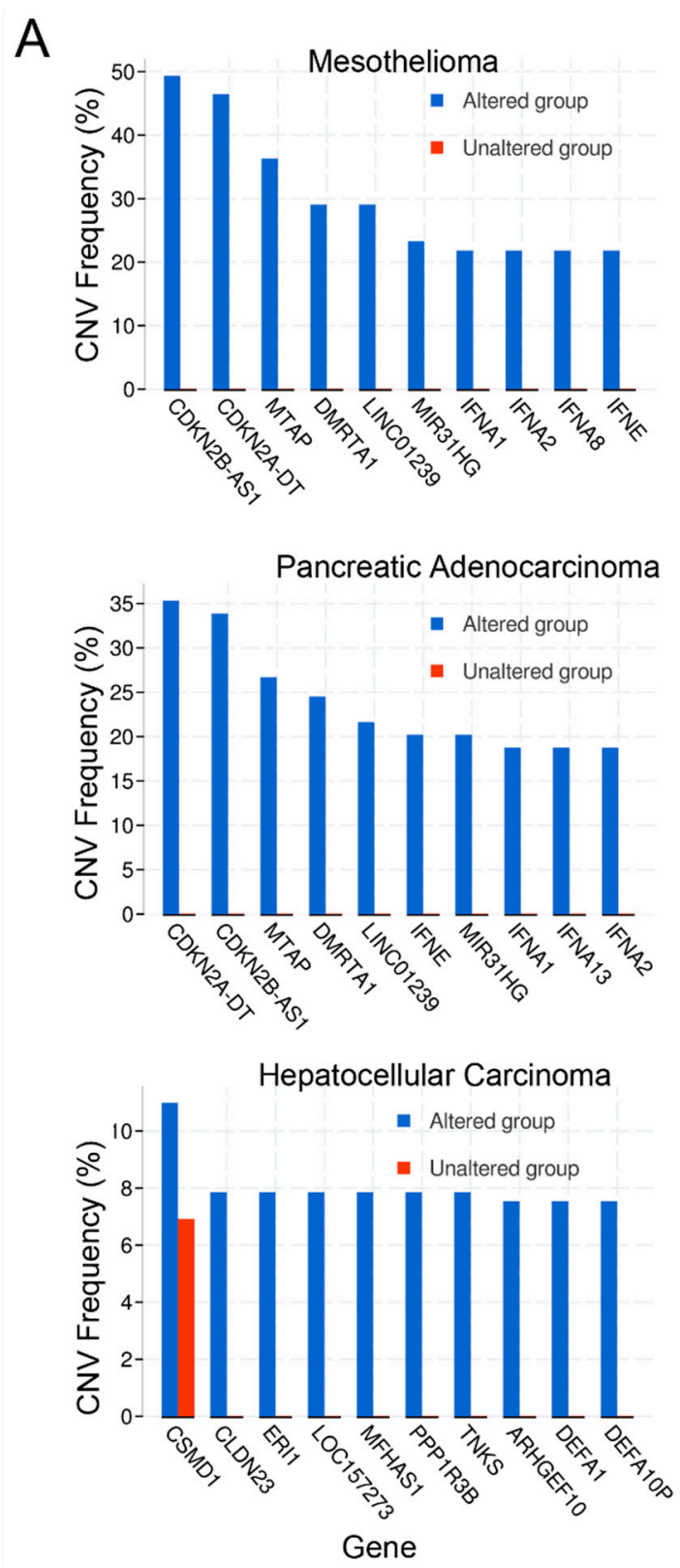
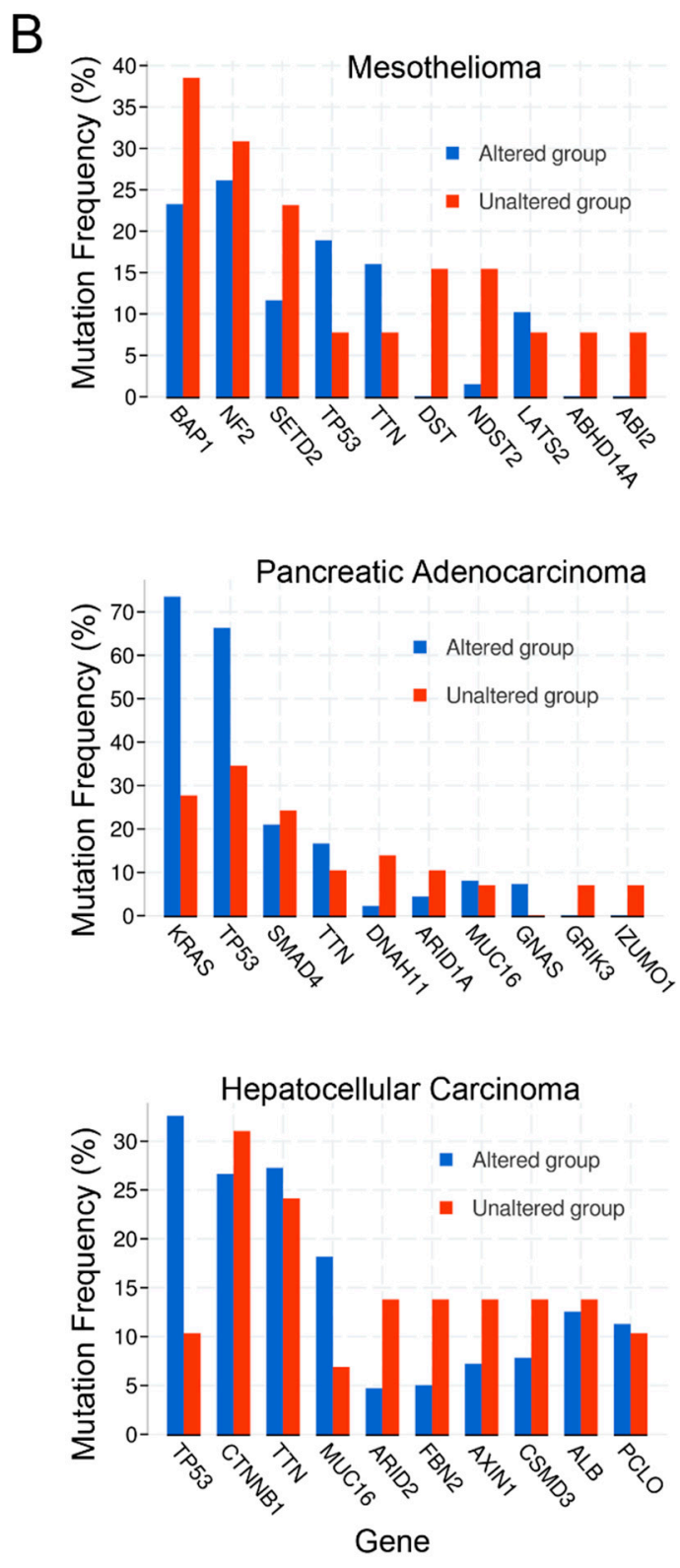

Figure 3. (A) Copy number variation (CNV) frequency; (B) Mutation frequency.

\subsection{Mutations}

Co-expression analysis of mutations in the cancer datasets was performed as well. The top genes with mutations are shown in Figure 3B. The top 3 genes with mutations in pancreatic cancer included RAS and TP53, as expected, in addition to SMAD4 (SMAD family member 4). For mesothelioma, the top genes with mutations were BAP1 (BRCA-associated protein 1), NF2 (neurofibromin 2), and SETD2 (SET domain containing 2, histone lysine methyltransferase). Of note, TP53 was the 4th most 
common mutation in mesothelioma. For hepatocellular carcinoma, the top gene mutations were TP53, CTNNB1 (catenin beta 1), and TTN (titin). TTN was also the 4 th most commonly mutated gene in pancreatic cancer. The top mutation profile for all three cancers reflected the two or three most common mutational drivers observed for each type of cancer as expected, with TP53 consistently playing a role in all of the cancer types $[41,45,46]$. Intriguingly, mitochondrial metabolism and ROS are considered essential for KRAS-mediated tumorigenicity [47].

\section{Discussion}

Mesothelioma, pancreatic cancer, and hepatocellular carcinoma are three of the most treatment-refractory cancers [1-3]. In the metastatic stages of each, there are no curative options, and current treatment options have very modest benefit [1-3]. New treatment paradigms are desperately needed. While TCGA analyses have been conducted previously for these tumors [40-42], descriptions of the TCGA-based analysis of each tumor cannot include all pathways of potential therapeutic application [40-42]. Based on previous studies, we chose to focus on select pathways that have therapeutic agents (the cell cycle and mitochondrial antioxidant defense), have not been analyzed in combination, and have not been studied thoroughly in treatment-refractory cancers. TCGA pairwise analysis with key pathway proteins indicated a notable correlation between the cell cycle CDKs 2 and 4 (negative) and CDK5 (positive) with mitochondrial antioxidant proteins in all three cancer types. Furthermore, NFKB1 and HIF1 expression were negatively correlated with CDK5 and TXN2 in all three cancers, while HIF1-NFKB1 showed a positive association with each other. Mounting evidence suggests that mitochondrial antioxidant defense plays a key role in the survival of non-replicating tumor initiating cells, intrinsic or acquired resistance to chemotherapeutic agents, and the metastases of tumors [48-53]. Furthermore, cell cycle CDKs 2 and 4 partner plus cyclins E and D1 have been shown to be downregulated in response to increased mitochondrial ROS or decreased ATP levels, both situations associated with TXN2 downregulation [54,55]. CDK4/cyclin D1 [56] and CDK4/cyclin $\mathrm{E}$ [57] are known to translocate to the mitochondria and can increase dramatically the activity of SOD2 (superoxide dismutase 2, Figure 4) in the absence of altering transcript or protein expression. It has been proposed that cell cycle progression is regulated in part via a mitochondria-mediated ROS mechanism [58]. Overall, cell cycle-related proteins and mitochondrial antioxidant defense proteins are important to the pathogenesis and growth of each of these cancers; therefore, we hypothesized that interactions may exist between these two pathways that may be amenable to targeting with agents already approved for other uses by the FDA. Drug "repurposing" (i.e., identification of new therapeutic applications for already approved drugs) is significantly more affordable and achievable, removing most of the expense, time, and high failure rate associated with novel drug development [59,60]. This strategy has great appeal for these three cancers due to their poor prognosis and limited market size, potentially achieving a rapid move to the clinic for identified new therapies.

\section{Conclusions}

Our study is the first to utilize the TCGA to evaluate the potential relationship between the cell cycle (and cell cycle-related proteins/genes) and mitochondrial antioxidant defense in three separate, treatment-refractory, cancers, namely pancreatic cancer, hepatocellular carcinoma, and mesothelioma. The potential relationships between the two pathways, based on key mRNA expression correlations and copy number variations, suggest that further laboratory-based studies to evaluate for synergistic interactions among inhibitors of each pathway may lead to new treatment strategies for at least a portion of these tumors. Of note, key inhibitors of the cell cycle pathway (i.e., palbociclib [16]) and mitochondrial antioxidant defense (i.e., auranofin [28]) are clinically approved by the FDA for other diseases; therefore, positive study results could lead to the design of early-stage clinical trials for these treatment-refractory cancers. 


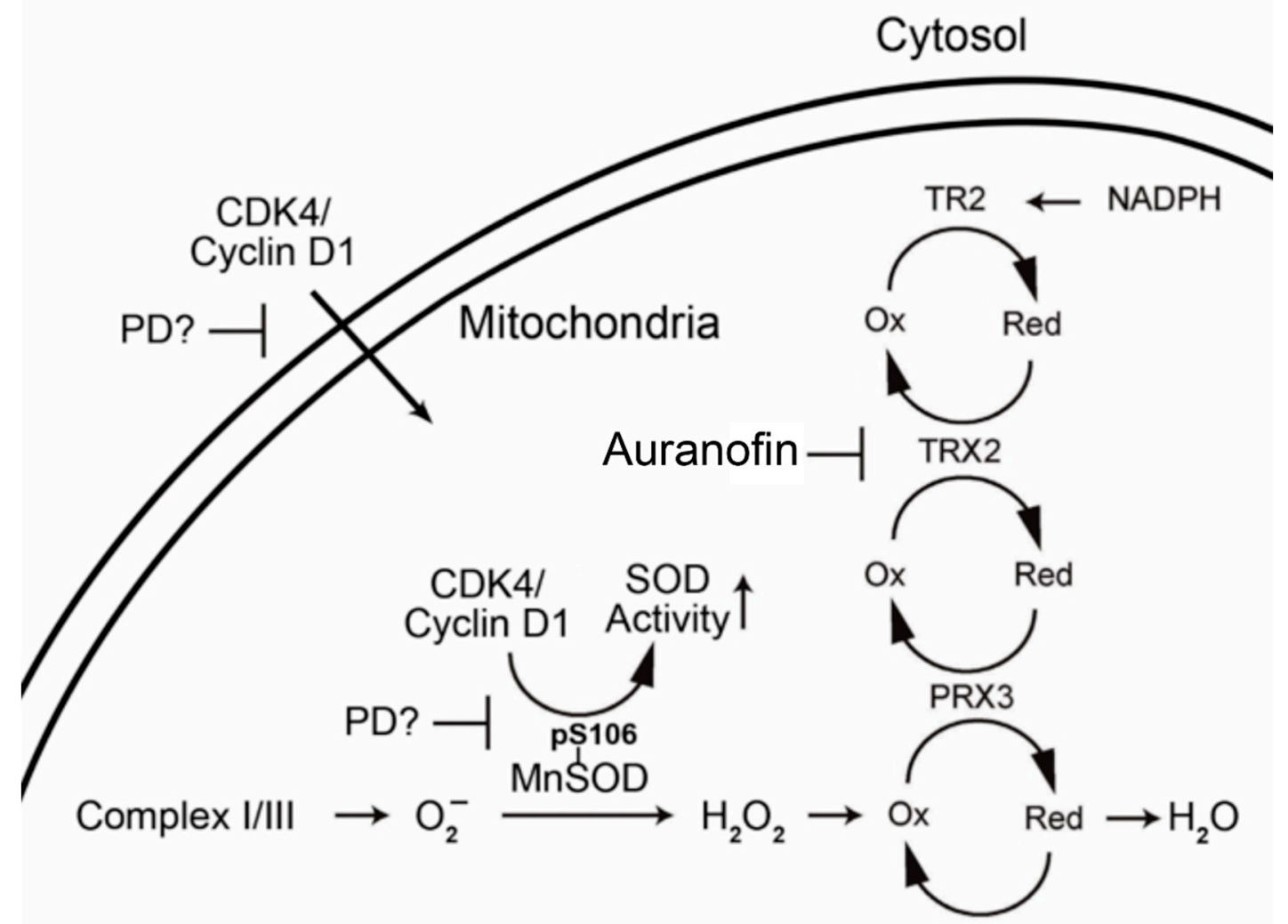

Figure 4. Proposed interaction of CDK4/cyclin D1 and mitochondrial antioxidant proteins.

\section{Materials and Methods}

All genomic data were obtained from The Cancer Genome Atlas (TCGA) via the web tool, cBioPortal $[43,44]$. A list of relevant genes from the cell cycle and mitochondrial antioxidant pathways was compiled by literature review and consensus of the authors [13-15,17,18,20-22,24,25,41,42,44]. The gene list was entered into the cBioPortal online tool. The online tool was used to identify overall survival and progression-free survival for the entire list of genes. Comparison is between genes with abnormalities (mutations, copy number variations, and mRNA expression levels). Subsequently, mRNA expression levels within tumors were compared with relevant mRNA expression levels of genes postulated to be related. Comparisons were made by Pearson's and Spearman's coefficients (tools included in cBioPortal) as it is unclear whether the postulated relationships are non-parametric or parametric. Additionally, the top copy number variations and mutations for each tumor type were also catalogued.

Supplementary Materials: The following are available online at http://www.mdpi.com/1424-8247/13/2/26/s1.

Author Contributions: G.S.S., B.T.K., and M.A.K. All conceived the study, collected and analyzed data, and wrote the manuscript. All authors have read and agreed to the published version of the manuscript.

Funding: This work was supported by a grant from the Department of Defense (CA120102, M.A.K.).

Acknowledgments: We would like to thank Janeen Trembley and Khalil Ahmed for valuable discussions.

Conflicts of Interest: The authors declare no conflict of interest.

\section{References}

1. Llovet, J.M.; Ricci, S.; Mazzaferro, V.; Hilgard, P.; Gane, E.; Blanc, J.F.; de Oliveira, A.C.; Santoro, A.; Raoul, J.L.; Forner, A.; et al. Sorafenib in advanced hepatocellular carcinoma. N. Engl. J. Med. 2008, 359, 378-390. [CrossRef] 
2. Vaccaro, V.; Sperduti, I.; Milella, M. FOLFIRINOX versus gemcitabine for metastatic pancreatic cancer. N. Engl. J. Med. 2011, 365, 768-769.

3. Vogelzang, N.J.; Rusthoven, J.J.; Symanowski, J.; Denham, C.; Kaukel, E.; Ruffie, P.; Gatzemeier, U.; Boyer, M.; Emri, S.; Manegold, C.; et al. Phase III study of pemetrexed in combination with cisplatin versus cisplatin alone in patients with malignant pleural mesothelioma. J. Clin. Oncol. Off. J. Am. Soc. Clin. Oncol. 2003, 21, 2636-2644. [CrossRef]

4. De Gooijer, C.J.; Baas, P.; Burgers, J.A. Current chemotherapy strategies in malignant pleural mesothelioma. Transl. Lung Cancer Res. 2018, 7, 574-583. [CrossRef]

5. Ikeda, M.; Morizane, C.; Ueno, M.; Okusaka, T.; Ishii, H.; Furuse, J. Chemotherapy for hepatocellular carcinoma: Current status and future perspectives. Jpn. J. Clin. Oncol. 2018, 48, 103-114. [CrossRef] [PubMed]

6. Springfeld, C.; Jager, D.; Buchler, M.W.; Strobel, O.; Hackert, T.; Palmer, D.H.; Neoptolemos, J.P. Chemotherapy for pancreatic cancer. Presse Med. 2019, 48, e159-e174. [CrossRef] [PubMed]

7. Zalcman, G.; Mazieres, J.; Margery, J.; Greillier, L.; Audigier-Valette, C.; Moro-Sibilot, D.; Molinier, O.; Corre, R.; Monnet, I.; Gounant, V.; et al. Bevacizumab for newly diagnosed pleural mesothelioma in the Mesothelioma Avastin Cisplatin Pemetrexed Study (MAPS): A randomised, controlled, open-label, phase 3 trial. Lancet 2016, 387, 1405-1414. [CrossRef]

8. Kudo, M.; Finn, R.S.; Qin, S.; Han, K.H.; Ikeda, K.; Piscaglia, F.; Baron, A.; Park, J.W.; Han, G.; Jassem, J.; et al. Lenvatinib versus sorafenib in first-line treatment of patients with unresectable hepatocellular carcinoma: A randomised phase 3 non-inferiority trial. Lancet 2018, 391, 1163-1173. [CrossRef]

9. Conroy, T.; Desseigne, F.; Ychou, M.; Bouche, O.; Guimbaud, R.; Becouarn, Y.; Adenis, A.; Raoul, J.L.; Gourgou-Bourgade, S.; de la Fouchardiere, C.; et al. FOLFIRINOX versus gemcitabine for metastatic pancreatic cancer. N. Engl. J. Med. 2011, 364, 1817-1825. [CrossRef]

10. Alley, E.W.; Lopez, J.; Santoro, A.; Morosky, A.; Saraf, S.; Piperdi, B.; van Brummelen, E. Clinical safety and activity of pembrolizumab in patients with malignant pleural mesothelioma (KEYNOTE-028): Preliminary results from a non-randomised, open-label, phase $1 \mathrm{~b}$ trial. Lancet Oncol. 2017, 18, 623-630. [CrossRef]

11. Zhu, A.X.; Finn, R.S.; Edeline, J.; Cattan, S.; Ogasawara, S.; Palmer, D.; Verslype, C.; Zagonel, V.; Fartoux, L.; Vogel, A.; et al. Pembrolizumab in patients with advanced hepatocellular carcinoma previously treated with sorafenib (KEYNOTE-224): A non-randomised, open-label phase 2 trial. Lancet Oncol. 2018, 19, 940-952. [CrossRef]

12. Benson, C.; Kaye, S.; Workman, P.; Garrett, M.; Walton, M.; de Bono, J. Clinical anticancer drug development: Targeting the cyclin-dependent kinases. Br. J. Cancer 2005, 92, 7-12. [CrossRef] [PubMed]

13. Frizelle, S.P.; Grim, J.; Zhou, J.; Gupta, P.; Curiel, D.T.; Geradts, J.; Kratzke, R.A. Re-expression of p16INK4a in mesothelioma cells results in cell cycle arrest, cell death, tumor suppression and tumor regression. Oncogene 1998, 16, 3087-3095. [CrossRef] [PubMed]

14. Kim, J.K.; Diehl, J.A. Nuclear cyclin D1: An oncogenic driver in human cancer. J. Cell. Physiol. 2009, 220, 292-296. [CrossRef]

15. Choi, Y.J.; Anders, L. Signaling through cyclin D-dependent kinases. Oncogene 2014, 33, 1890-1903. [CrossRef]

16. Cadoo, K.A.; Gucalp, A.; Traina, T.A. Palbociclib: An evidence-based review of its potential in the treatment of breast cancer. Breast Cancer 2014, 6, 123-133.

17. De Assis, L.V.; Locatelli, J.; Isoldi, M.C. The role of key genes and pathways involved in the tumorigenesis of Malignant Mesothelioma. Biochim. Biophys. Acta 2014, 1845, 232-247. [CrossRef]

18. Cen, L.; Carlson, B.L.; Schroeder, M.A.; Ostrem, J.L.; Kitange, G.J.; Mladek, A.C.; Fink, S.R.; Decker, P.A.; $\mathrm{Wu}, \mathrm{W}$; Kim, J.S.; et al. p16-Cdk4-Rb axis controls sensitivity to a cyclin-dependent kinase inhibitor PD0332991 in glioblastoma xenograft cells. Neuro Oncol. 2012, 14, 870-881. [CrossRef]

19. Brautigam, L.; Schutte, L.D.; Godoy, J.R.; Prozorovski, T.; Gellert, M.; Hauptmann, G.; Holmgren, A.; Lillig, C.H.; Berndt, C. Vertebrate-specific glutaredoxin is essential for brain development. Proc. Natl. Acad. Sci. USA 2011, 108, 20532-20537. [CrossRef]

20. Nonn, L.; Williams, R.R.; Erickson, R.P.; Powis, G. The absence of mitochondrial thioredoxin 2 causes massive apoptosis, exencephaly, and early embryonic lethality in homozygous mice. Mol. Cell. Biol. 2003, 23, 916-922. [CrossRef] 
21. Perez, V.I.; Lew, C.M.; Cortez, L.A.; Webb, C.R.; Rodriguez, M.; Liu, Y.; Qi, W.; Li, Y.; Chaudhuri, A.; Van Remmen, H.; et al. Thioredoxin 2 haploinsufficiency in mice results in impaired mitochondrial function and increased oxidative stress. Free Radic. Biol. Med. 2008, 44, 882-892. [CrossRef] [PubMed]

22. Hansen, J.M.; Zhang, H.; Jones, D.P. Mitochondrial thioredoxin-2 has a key role in determining tumor necrosis factor-alpha-induced reactive oxygen species generation, NF-kappaB activation, and apoptosis. Toxicol. Sci. 2006, 91, 643-650. [CrossRef] [PubMed]

23. Benhar, M.; Forrester, M.T.; Hess, D.T.; Stamler, J.S. Regulated protein denitrosylation by cytosolic and mitochondrial thioredoxins. Science 2008, 320, 1050-1054. [CrossRef] [PubMed]

24. Tanaka, T.; Hosoi, F.; Yamaguchi-Iwai, Y.; Nakamura, H.; Masutani, H.; Ueda, S.; Nishiyama, A.; Takeda, S.; Wada, H.; Spyrou, G.; et al. Thioredoxin-2 (TRX-2) is an essential gene regulating mitochondria-dependent apoptosis. EMBO J. 2002, 21, 1695-1703. [CrossRef] [PubMed]

25. Damdimopoulos, A.E.; Miranda-Vizuete, A.; Pelto-Huikko, M.; Gustafsson, J.A.; Spyrou, G. Human mitochondrial thioredoxin. Involvement in mitochondrial membrane potential and cell death. J. Biol. Chem. 2002, 277, 33249-33257. [CrossRef] [PubMed]

26. Rigobello, M.P.; Folda, A.; Baldoin, M.C.; Scutari, G.; Bindoli, A. Effect of auranofin on the mitochondrial generation of hydrogen peroxide. Role of thioredoxin reductase. Free Radic. Res. 2005, 39, 687-695. [CrossRef]

27. Cox, A.G.; Brown, K.K.; Arner, E.S.; Hampton, M.B. The thioredoxin reductase inhibitor auranofin triggers apoptosis through a Bax/Bak-dependent process that involves peroxiredoxin 3 oxidation. Biochem. Pharmacol. 2008, 76, 1097-1109. [CrossRef]

28. Schuh, E.; Pfluger, C.; Citta, A.; Folda, A.; Rigobello, M.P.; Bindoli, A.; Casini, A.; Mohr, F. Gold(I) carbene complexes causing thioredoxin 1 and thioredoxin 2 oxidation as potential anticancer agents. J. Med. Chem. 2012, 55, 5518-5528. [CrossRef]

29. Okrah, K.; Tarighat, S.; Liu, B.; Koeppen, H.; Wagle, M.C.; Cheng, G.; Sun, C.; Dey, A.; Chang, M.T.; Sumiyoshi, T.; et al. Transcriptomic analysis of hepatocellular carcinoma reveals molecular features of disease progression and tumor immune biology. NPJ Precis. Oncol. 2018, 2, 25. [CrossRef]

30. Zhang, X.; De Milito, A.; Demiroglu-Zergeroglu, A.; Gullbo, J.; D'Arcy, P.; Linder, S. Eradicating Quiescent Tumor Cells by Targeting Mitochondrial Bioenergetics. Trends Cancer 2016, 2, 657-663. [CrossRef]

31. Zhang, X.; Fryknas, M.; Hernlund, E.; Fayad, W.; De Milito, A.; Olofsson, M.H.; Gogvadze, V.; Dang, L.; Pahlman, S.; Schughart, L.A.; et al. Induction of mitochondrial dysfunction as a strategy for targeting tumour cells in metabolically compromised microenvironments. Nat. Commun. 2014, 5, 3295. [CrossRef]

32. Bollard, J.; Miguela, V.; Ruiz de Galarreta, M.; Venkatesh, A.; Bian, C.B.; Roberto, M.P.; Tovar, V.; Sia, D.; Molina-Sanchez, P.; Nguyen, C.B.; et al. Palbociclib (PD-0332991), a selective CDK4/6 inhibitor, restricts tumour growth in preclinical models of hepatocellular carcinoma. Gut 2016, 66, 1286-1296. [CrossRef]

33. Franco, J.; Balaji, U.; Freinkman, E.; Witkiewicz, A.K.; Knudsen, E.S. Metabolic Reprogramming of Pancreatic Cancer Mediated by CDK4/6 Inhibition Elicits Unique Vulnerabilities. Cell Rep. 2016, 14, 979-990. [CrossRef] [PubMed]

34. Bonelli, M.A.; Digiacomo, G.; Fumarola, C.; Alfieri, R.; Quaini, F.; Falco, A.; Madeddu, D.; La Monica, S.; Cretella, D.; Ravelli, A.; et al. Combined Inhibition of CDK4/6 and PI3K/AKT/mTOR Pathways Induces a Synergistic Anti-Tumor Effect in Malignant Pleural Mesothelioma Cells. Neoplasia 2017, 19, 637-648. [CrossRef] [PubMed]

35. Rotblat, B.; Grunewald, T.G.; Leprivier, G.; Melino, G.; Knight, R.A. Anti-oxidative stress response genes: Bioinformatic analysis of their expression and relevance in multiple cancers. Oncotarget 2013, 4, 2577-2590. [CrossRef] [PubMed]

36. Song, I.S.; Jeong, Y.J.; Han, J. Mitochondrial metabolism in cancer stem cells: A therapeutic target for colon cancer. BMB Rep. 2015, 48, 539-540. [CrossRef]

37. Anders, L.; Ke, N.; Hydbring, P.; Choi, Y.J.; Widlund, H.R.; Chick, J.M.; Zhai, H.; Vidal, M.; Gygi, S.P.; Braun, P.; et al. A systematic screen for CDK4/6 substrates links FOXM1 phosphorylation to senescence suppression in cancer cells. Cancer Cell 2011, 20, 620-634. [CrossRef]

38. Roder, C.; Thomson, M.J. Auranofin: Repurposing an old drug for a golden new age. Drugs R D 2015, 15, 13-20. [CrossRef]

39. Wang, Z.; Jensen, M.A.; Zenklusen, J.C. A Practical Guide to The Cancer Genome Atlas (TCGA). Methods Mol. Biol. 2016, 1418, 111-141. 
40. The Cancer Genome Atlas Research Network. Electronic address aadhe, Cancer Genome Atlas Research, N. Integrated Genomic Characterization of Pancreatic Ductal Adenocarcinoma. Cancer Cell 2017, 32, 185-203. [CrossRef]

41. Cancer Genome Atlas Research Network. Electronic address wbe, Cancer Genome Atlas Research, N. Comprehensive and Integrative Genomic Characterization of Hepatocellular Carcinoma. Cell 2017, 169, 1327-1341. [CrossRef] [PubMed]

42. Hmeljak, J.; Sanchez-Vega, F.; Hoadley, K.A.; Shih, J.; Stewart, C.; Heiman, D.; Tarpey, P.; Danilova, L.; Drill, E.; Gibb, E.A.; et al. Integrative Molecular Characterization of Malignant Pleural Mesothelioma. Cancer Discov. 2018, 8, 1548-1565. [CrossRef] [PubMed]

43. Cerami, E.; Gao, J.; Dogrusoz, U.; Gross, B.E.; Sumer, S.O.; Aksoy, B.A.; Jacobsen, A.; Byrne, C.J.; Heuer, M.L.; Larsson, E.; et al. The cBio cancer genomics portal: An open platform for exploring multidimensional cancer genomics data. Cancer Discov. 2012, 2, 401-404. [CrossRef] [PubMed]

44. Gao, J.; Aksoy, B.A.; Dogrusoz, U.; Dresdner, G.; Gross, B.; Sumer, S.O.; Sun, Y.; Jacobsen, A.; Sinha, R.; Larsson, E.; et al. Integrative analysis of complex cancer genomics and clinical profiles using the cBioPortal. Sci. Signal 2013, 6. [CrossRef] [PubMed]

45. De Rienzo, A.; Archer, M.A.; Yeap, B.Y.; Dao, N.; Sciaranghella, D.; Sideris, A.C.; Zheng, Y.; Holman, A.G.; Wang, Y.E.; Dal Cin, P.S.; et al. Gender-Specific Molecular and Clinical Features Underlie Malignant Pleural Mesothelioma. Cancer Res. 2016, 76, 319-328. [CrossRef] [PubMed]

46. Pelosi, E.; Castelli, G.; Testa, U. Pancreatic Cancer: Molecular Characterization, Clonal Evolution and Cancer Stem Cells. Biomedicines 2017, 5, 65. [CrossRef]

47. Weinberg, F.; Hamanaka, R.; Wheaton, W.W.; Weinberg, S.; Joseph, J.; Lopez, M.; Kalyanaraman, B.; Mutlu, G.M.; Budinger, G.R.; Chandel, N.S. Mitochondrial metabolism and ROS generation are essential for Kras-mediated tumorigenicity. Proc. Natl. Acad. Sci. USA 2010, 107, 8788-8793. [CrossRef]

48. Piskounova, E.; Agathocleous, M.; Murphy, M.M.; Hu, Z.; Huddlestun, S.E.; Zhao, Z.; Leitch, A.M.; Johnson, T.M.; DeBerardinis, R.J.; Morrison, S.J. Oxidative stress inhibits distant metastasis by human melanoma cells. Nature 2015, 527, 186-191. [CrossRef]

49. Sarosiek, K.A.; Ni Chonghaile, T.; Letai, A. Mitochondria: Gatekeepers of response to chemotherapy. Trends Cell Biol. 2013, 23, 612-619. [CrossRef]

50. Funes, J.M.; Quintero, M.; Henderson, S.; Martinez, D.; Qureshi, U.; Westwood, C.; Clements, M.O.; Bourboulia, D.; Pedley, R.B.; Moncada, S.; et al. Transformation of human mesenchymal stem cells increases their dependency on oxidative phosphorylation for energy production. Proc. Natl. Acad. Sci. USA 2007, 104, 6223-6228. [CrossRef]

51. Le, A.; Stine, Z.E.; Nguyen, C.; Afzal, J.; Sun, P.; Hamaker, M.; Siegel, N.M.; Gouw, A.M.; Kang, B.H.; $\mathrm{Yu}$, S.H.; et al. Tumorigenicity of hypoxic respiring cancer cells revealed by a hypoxia-cell cycle dual reporter. Proc. Natl. Acad. Sci. USA 2014, 111, 12486-12491. [CrossRef] [PubMed]

52. Policastro, L.L.; Ibanez, I.L.; Notcovich, C.; Duran, H.A.; Podhajcer, O.L. The tumor microenvironment: Characterization, redox considerations, and novel approaches for reactive oxygen species-targeted gene therapy. Antioxid. Redox Signal. 2013, 19, 854-895. [CrossRef] [PubMed]

53. Smolkova, K.; Plecita-Hlavata, L.; Bellance, N.; Benard, G.; Rossignol, R.; Jezek, P. Waves of gene regulation suppress and then restore oxidative phosphorylation in cancer cells. Int. J. Biochem. Cell Biol. 2011, 43, 950-968. [CrossRef] [PubMed]

54. Fu, X.F.; Yao, K.; Du, X.; Li, Y.; Yang, X.Y.; Yu, M.; Li, M.Z.; Cui, Q.H. PGC-1alpha regulates the cell cycle through ATP and ROS in CH1 cells. J. Zhejiang Univ. Sci. B 2016, 17, 136-146. [CrossRef] [PubMed]

55. Mandal, S.; Freije, W.A.; Guptan, P.; Banerjee, U. Metabolic control of G1-S transition: Cyclin E degradation by p53-induced activation of the ubiquitin-proteasome system. J. Cell Biol. 2010, 188, 473-479. [CrossRef] [PubMed]

56. Jin, C.; Qin, L.; Shi, Y.; Candas, D.; Fan, M.; Lu, C.L.; Vaughan, A.T.; Shen, R.; Wu, L.S.; Liu, R.; et al. CDK4-mediated MnSOD activation and mitochondrial homeostasis in radioadaptive protection. Free Radic. Biol. Med. 2015, 81, 77-87. [CrossRef]

57. Wolf, D.A. Is reliance on mitochondrial respiration a "chink in the armor" of therapy-resistant cancer? Cancer Cell 2014, 26, 788-795. [CrossRef]

58. Sarsour, E.H.; Kalen, A.L.; Goswami, P.C. Manganese superoxide dismutase regulates a redox cycle within the cell cycle. Antioxid. Redox Signal. 2014, 20, 1618-1627. [CrossRef] 
59. Woodcock, J.; Woosley, R. The FDA critical path initiative and its influence on new drug development. Annu. Rev. Med. 2008, 59, 1-12. [CrossRef]

60. Pessetto, Z.Y.; Weir, S.J.; Sethi, G.; Broward, M.A.; Godwin, A.K. Drug repurposing for gastrointestinal stromal tumor. Mol. Cancer Ther. 2013, 12, 1299-1309. [CrossRef]

(C) 2020 by the authors. Licensee MDPI, Basel, Switzerland. This article is an open access article distributed under the terms and conditions of the Creative Commons Attribution (CC BY) license (http://creativecommons.org/licenses/by/4.0/). 